\title{
RADIOACTIVITY IN SEDIMENTS OF THE GREAT LAKES: POST-DEPOSITIONAL REDISTRIBUTION BY DEPOSIT-FEEDING ORGANISMS
}

\author{
J.A. ROBBINS, J.R. KREZOSKI and S.C. MOZLEY \\ Great Lakes Research Division, University of Michigan, Ann Arbor, Mich. (USA)
}

Received February 7, 1977

Revised version received May 26, 1977

\begin{abstract}
At two locations in southern Lake Huron (U.S.A.), twelve $35.5-\mathrm{cm}$ diameter cores of fine-grained sediments were taken for comparison of the vertical distributions of ${ }^{210} \mathrm{~Pb}$ and fallout ${ }^{137} \mathrm{Cs}$ with the distributions of benthic macroinvertebrates, mainly oligochaete worms (Tubificidae) and the amphipod, Pontoporeia affinis. Locations were selected on the basis of ${ }^{210} \mathrm{~Pb}$ distributions measured a year earlier which indicated contrasting depths of mixing of surface sediments. At one location the activity of ${ }^{210} \mathrm{~Pb}$ is uniform down to about $6 \mathrm{~cm}$ and $95 \%$ of total invertebrates occur within this zone; at the other location the zone of constant activity is only $3 \mathrm{~cm}$ deep but $90 \%$ of the invertebrates occur within it. Comparison of published tubificid defecation rates with sediment accumulation rates based on $210 \mathrm{~Pb}$ shows that oligochaetes alone can account for mixing in one case while the effects of amphipods may be required in the case of shallower mixing. If mixing is represented as a diffusional process, eddy diffusion coefficients are at least 5.8 and $3.3 \mathrm{~cm}^{2} \mathrm{yr}^{-1}$ at respective locations. In comparison with bioturbation, molecular diffusion is of minor importance in the post-depositional mobility of ${ }^{137} \mathrm{Cs}$. The necessity for introducing a diffusion coefficient varying continuously with depth is indicated by characteristics of the distribution of ${ }^{137} \mathrm{Cs}$. Biological reworking of near-surface sediments is an important process affecting radioactivity and chemical profiles in profundal deposits of this and probably other Great Lakes.
\end{abstract}

\section{Introduction}

Recent studies of lead [1] as well as natural and fallout radioactivity $\left({ }^{210} \mathrm{~Pb},{ }^{137} \mathrm{Cs}\right.$ and $\left.{ }^{239} \mathrm{Pu}[2-6]\right)$ in sediments from several of the North American Great Lakes have shown that concentration and decay-corrected activity profiles most often do not accurately reflect the known history of inputs to these lakes. As the residence times of such elements in freshwater are known to be very short, the lack of correspondence between inputs and sedimentary records is probably due to post-depositional processes rather than to integrative effects in the water column. An accurate reconstruction of the radioactivity as well as chemical history of the Great Lakes will therefore depend on a proper understanding of post-depositional processes affecting recent sedimentary records.

Indirect evidence for biological mixing of near- surface sediments has been obtained from profiles of the uranium-series nuclides, particularly ${ }^{210} \mathrm{~Pb}$ $\left(t_{1 / 2}=22.26\right.$ years $)$. There is growing interest in the use of this radionuclide to date coastal marine and lacustrine sediments deposited during the past century or so $[1-3,5-9] .{ }^{210} \mathrm{~Pb}$, which originates from decay of atmospheric radon, is delivered primarily in rain to surface waters and is rapidly transferred to underlying deposits $[10,11]$. When the flux of ${ }^{210} \mathrm{~Pb}$ to sediments and the sedimentation rate are constant the vertical distribution of unsupported ${ }^{210} \mathrm{~Pb}$ should decrease exponentially with depth as a result of radioactive decay during burial. Actual distributions of unsupported ${ }^{210} \mathrm{~Pb}$ in sediments from Lakes Superior [6], Michigan [3], and Huron [5] often exhibit reduced or constant activity within a zone of varying depth at the sediment-water interface. Because distributions with such features are characteristically found in deposits known or believed 
to support populations of mobile benthic organisms, constant near-surface activity has been ascribed to biological mixing [1-9]. Evidence for the influence of benthic organisms on radioactivity profiles has remained largely circumstantial although two recent studies of uranium-series nuclides in estuarine sediment of Long Island Sound have more directly established the role of benthic fauna. Thomson et al. [12] found an altered distribution of ${ }^{210} \mathrm{~Pb}$ within the upper several centimeters of a sediment core where X-radiographs revealed uniform stratigraphy, in comparison with laminated deeper sediments. They attributed loss of structure in near-surface sediments to biological reworking. Subsequently Aller and Cochran [13] related the distribution of ${ }^{234} \mathrm{Th}$ $\left(t_{1 / 2}=24\right.$ days $)$ in near-surface sediments from the Sound to the activities of deposit-feeding bivalves and other zoobenthos.

In the Great Lakes large populations of oligochaete worms and the amphipod, Pontoporeia affinis occur widely in profundal sediments [14]. The burrowing and feeding activities of natural mixed populations of tubificid oligochaetes are known to loosen and mix sediments to depths on the order of ten centimeters with resultant blurring of the stratigraphic record and induction of chemical changes near the sediment-water interface $[15,16]$. Therefore it is expected that such infaunal organisms would widely influence radioactivity profiles in sediments of the Great Lakes. To assess their role we have directly compared the vertical distribution of the major mobile species with the distributions of ${ }^{210} \mathrm{~Pb}$ and ${ }^{137} \mathrm{Cs}$ in a series of cores from two locations in southern Lake Huron where previous ${ }^{210} \mathrm{~Pb}$ data indicated strongly contrasting depths of mixing [5].

\section{Methods}

Sediment samples were obtained with a gravity corer (Benthos, Inc.) having a butyrate-plastic liner $\left(35.5 \mathrm{~cm}^{2}\right)$. In order to preserve the integrity of unconsolidated surface sediments the core liners were not equipped with the core cutter assembly or sediment retainer but operated in an open-tube mode, approaching the sediment surface at less than freefall velocity. This procedure is among the most effective known for sampling soft-bottom benthic com- munities $[17,18]$. The retrieval of undisturbed sediments is of critical importance for this study. In cores collected elsewhere in Lake Huron from similar finegrained, fluid sediments which support chironomid larval populations, we observed intact burrow tubes projecting several millimeters above the sedimentwater interface. Evidently our coring method preserves the integrity of these delicate structures. However the effect of the coring event on the vertical distribution of the benthic organisms is uncertain and little can be done to prevent the possible movement of organisms in response to the shock of corer entry into the sediments [18].

All cores, maintained in a vertical position, were extruded hydraulically and sectioned in centimeter intervals aboard ship within thirty minutes of collection. At station 14, centered in the northern area of the Goderich depositional basin [19], the sediments consist of a brown (oxidized) fluid (85-95\% porosity) silt in the upper $4 \mathrm{~cm}$ overlying uniform firmer, gray, slightly sandy silt. At station 18 , which is located toward the shoreward margin of the same depositional basin, the brown silty material occurred only in the upper centimeter of sediment with underlying sediment being a uniform firmer, dark gray, slightly sandy silt. Centimeter-thick sections of each of twelve cores collected at each location for benthos analysis plus sections of additional cores for radioactivity analysis were preserved respectively with formalin and by freezing for later processing in the laboratory. Details of methods for analysis of benthic organisms are reported elsewhere [20]. The activity of ${ }^{210} \mathrm{~Pb}$ was determined by alpha proportional counting of the ${ }^{210} \mathrm{~Pb}$ daughter self-plated on to silver disks from acid extracts of freeze-dried sediments [3]. The ${ }^{137} \mathrm{Cs}$ activity of whole dried sediment was measured by conventional gamma counting using a $\mathrm{NaI}$ scintillation detector/multichannel analyzer system.

\section{Theoretical considerations}

\subsection{Distribution of ${ }^{210} \mathrm{~Pb}$ in undisturbed sediments.}

When the sedimentation rate $\omega\left(\mathrm{cm} \mathrm{yr}^{-1}\right)$ and activity of unsupported ${ }^{210} \mathrm{~Pb}$ added to the sediment surface, $A_{\mathrm{s}}\left(\mathrm{dpm}^{-1}\right)$, are constant in time, the dis- 
tribution of unsupported ${ }^{210} \mathrm{~Pb}$ is given by:

$A=A_{\mathrm{s}} \mathrm{e}^{-\lambda z / \omega}$

where $\lambda=0.693 / 22.26\left(\mathrm{yr}^{-1}\right)$ and $z(\mathrm{~cm})$ is the depth below the sediment-water interface [7-9]. In sediments where compaction is significant, the above equation is applicable provided $z$ and $\omega$ are expressed in units of $\mathrm{g} \mathrm{cm}^{-2}$ and $\mathrm{g} \mathrm{cm}^{-2} \mathrm{yr}^{-1}$, respectively. As we have noted the activity of ${ }^{210} \mathrm{~Pb}$ is of ten constant over depths from 2 to $8 \mathrm{~cm}$ in sediments of the Great Lakes $[3,5,6]$, thus equation 1 does not usually provide a satisfactory representation of measured ${ }^{210} \mathrm{~Pb}$ profiles.

\subsection{Rapid steady-state mixing}

Robbins and Edgington [3] showed that rapid steady-state mixing of sediments within a welldefined zone at the sediment-water interface can account for measured distributions of ${ }^{210} \mathrm{~Pb}$ in sediments from Lake Michigan. Subsequently they found that stable lead profiles could also be quantitatively described by application of the same theoretical model [1]. Their model, similar to that developed by Berger and Heath [21], requires that material added to the sediment surface be instantly distributed uniformly throughout a zone of fixed thickness, $s(\mathrm{~cm})$, at the sediment-water interface. As this mixed zone moves upward at the sedimentation rate $\omega$, material is transferred to underlying deposits (historical sediments) where no further redistribution (mixing) occurs. The quantitative effect of this mixing process on the distribution of ${ }^{210} \mathrm{~Pb}$ can be determined simply from considerations of mass balance. The flux of ${ }^{210} \mathrm{~Pb}$ (or ${ }^{137} \mathrm{Cs}$ ) into the mixed zone is $\rho_{\mathrm{s}}(1-$ $\phi) A_{\mathrm{s}} \omega\left(\mathrm{dpm} \mathrm{cm} \mathrm{yr}^{-2} \mathrm{yr}^{-1}\right)$ where $\rho_{\mathrm{s}}$ is the density of sediment solids $\left(\mathrm{g} \mathrm{cm}^{-3}\right)$ and $\phi$ is the porosity. The decay in the mixed layer is $\rho_{\mathrm{s}}(1-\phi) A_{\mathrm{m}} \lambda s$ where $A_{\mathrm{m}}$ is the activity in the mixed zone $\left(\mathrm{dpm} \mathrm{g}^{-1}\right)$ and the flux through the bottom is $\rho_{\mathrm{s}}(1-\phi) A_{\mathrm{m}} \omega$. Thus the change in total activity in the mixed zone is:

$\frac{\mathrm{d} A_{\mathrm{T}}}{\mathrm{d} t}=\rho_{\mathrm{s}}(1-\phi) A_{\mathrm{s}} \omega-\rho_{\mathrm{s}}(1-\phi) A_{\mathrm{m}}(\lambda s+\omega)$

where the total activity in the mixed layer is:

$A_{\mathrm{T}}=\rho_{\mathrm{s}}(1-\phi) A_{\mathrm{m}} s$

Thus eliminating $A_{\mathrm{T}}$ from equation 2 using equation
3 and dividing through by $\rho_{\mathrm{s}}(1-\phi) s$ gives:

$\frac{\mathrm{d} A_{\mathrm{m}}}{\mathrm{d} t}=A_{\mathrm{s}}(\omega / s)-A_{\mathrm{m}}(\lambda+\omega / s)$

for ${ }^{210} \mathrm{~Pb}, A_{\mathrm{s}}$ is constant and $\mathrm{d} A_{\mathrm{m}} / \mathrm{d} t=0$ so that:

$A_{\mathrm{m}}=A_{\mathrm{s}} /(1+\lambda s / \omega)$

Thus the distribution of unsupported ${ }^{210} \mathrm{~Pb}$ is:

$\left.\begin{array}{ll}A=A_{\mathrm{m}} & z \leqslant s \\ A=A_{\mathrm{m}} \mathrm{e}^{-\lambda(z-s) / \omega} & z>s\end{array}\right\}$

where the exponential term in the second part of equation 6 represents radioactive decay following incorporation of ${ }^{210} \mathrm{~Pb}$ into historical layers. The effect of steady-state, rapid mixing of surface sedimetns is to reduce the activity of ${ }^{210} \mathrm{~Pb}$ from its value at the surface of unmixed sediments by the factor $(1+s \lambda / \omega)$

\subsection{Solution for a time-dependent flux}

For ${ }^{137} \mathrm{Cs}$ the added activity, $A_{\mathrm{s}}$, is time-dependent. The solution to equation 4 for the activity within the mixed zone is then:

$A_{\mathrm{m}}(t)=\gamma \mathrm{e}^{-(\gamma+\lambda) t} \int_{0}^{t} \mathrm{e}^{+(\gamma+\lambda) \tau} A_{\mathrm{s}}(\tau) \mathrm{d} \tau$

where $\gamma=s / \omega$ and $t=0$ corresponds to a sufficiently deep sediment layer. The distribution is then:

$\left.\begin{array}{ll}A=A_{\mathrm{m}}(T) & z \leqslant s \\ A=A_{\mathrm{m}}[T-(z-s) / \omega] \mathrm{e}^{-\lambda(z-s) / \omega} & z>s\end{array}\right)$

where $t=T$ corresponds to the sediment-water interface. See Edgington and Robbins [1] for additional details.

\subsection{Mixing as a diffusional process}

In the above model, the nature of the mixing process is left completely unspecified. It is required only that particles within the mixed zone redistribute rapidly in comparison with the rate of addition of new material so that the net effect is one of complete homogenization. When mixing is incomplete, in the above sense, the distribution of activity 
becomes sensitive to details of how particles are redistributed within the mixed zone. Although the process of mixing is known to be particle-selective [15] and to involve enhanced transfer between certain layers, as in the case of "conveyor belt" species [24], representation of mixing as a process akin to diffusion has met with some success $[8,9,2,28]$. In terms of the eddy diffusion of sediment solids, and unsupported ${ }^{210} \mathrm{~Pb}$ (or ${ }^{137} \mathrm{Cs}$ ), the distribution of activity is given as a solution to the diffusion equation:

$\frac{\partial}{\partial z}\left(K_{\mathrm{b}} \frac{\partial A}{\partial z}\right)-\omega \frac{\partial A}{\partial z}-\lambda A=\frac{\partial A}{\partial t}$

where $K_{b}$ is the eddy diffusion of mixing coefficient $\left(\mathrm{cm}^{2} \mathrm{yr}^{-1}\right)$ characteristic of the mixing process and is depth-dependent in principle. Existing diffusion models $[8,9,28,29]$ have retained the concept of a well-defined zone of mixing within which $K_{\mathrm{b}}$ is constant (i.e. $K_{\mathrm{b}}=0$ for $z>s$ ). Under these conditions the above time-dependent equation simplifies to:

$$
\left.\begin{array}{ll}
K_{\mathrm{b}} \frac{\partial^{2} A}{\partial z}-\omega \frac{\partial A}{\partial z}-\lambda A=0 & z \leqslant s \\
-\omega \frac{\partial A}{\partial z}-\lambda A=0 & z>s
\end{array}\right\}
$$

Solutions to this set of equations for $\partial A / \partial t \neq 0$ with boundary conditions appropriate for studying the effect of mixing on the time evolution of a profile resulting from a time-dependent input to surface sediments are developed by Guinasso and Schink [29]. For ${ }^{210} \mathrm{~Pb}$ where $\partial A / \partial t=0$ the solution to equation 10 is identical to that of equation 6 as $K_{\mathrm{b}} \rightarrow \infty$ [9]. Similarly for a time-dependent input the solution to equation 10 must reduce to equation 8 as $K_{b} \rightarrow \infty$. In the present study the utility of introducing the diffusion representation is twofold: (1) a lower limit for the value of $K_{\mathrm{b}}$ may be obtained from ${ }^{210} \mathrm{~Pb}$ distributions where complete homogenization of surface sediments is evident, and (2) equation provides a basis for theoretical treatment of distributions sensitive to a continuously variable depth dependence of the mixing coefficient. According to Guinasso and Schink [29], homogenization of sediments within the mixed zone will occur if:

$K_{\mathrm{b}} \gtrsim 10 \cdot \omega \cdot s$

\section{Results and discussion}

The vertical distributions of unsupported ${ }^{210} \mathrm{~Pb}$ shown in Fig. 1 exhibit a constant activity within the upper $6 \mathrm{~cm}$ at station 14 and $3 \mathrm{~cm}$ at station $18 \mathrm{fol}$ lowed in each case by an exponential decrease in activity below these respective depths. The activity of ${ }^{137} \mathrm{Cs}$ is also constant over a corresponding but somewhat smaller depth interval. The vertical distributions of each radionuclide are a persistent feature at each coring location being very reproducible from one year to the next (open circles, 1974 data; solid circles, 1975 data). The reproducibility of the distributions argues against the possibility of random core disturbances during sampling. However, our sampling procedure could conceivably result in systematic and reproducible homogenization of surface sediments, but consider the distributions at station 14. On successive years we observe constant activity down to $6 \mathrm{~cm}$. This zone is apparently welldefined $( \pm 0.5 \mathrm{~cm})$ and there is no gross discontinuity in activity at this depth. Suppose that prior to the coring event the distribution was in fact exponential as given by equation 1 . Then the unsupported activity

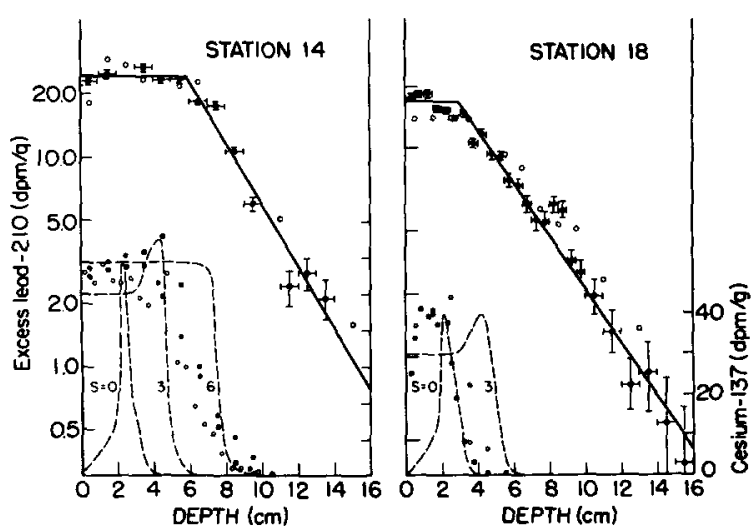

Fig. 1. The vertical distribution of unsupported $210 \mathrm{~Pb}(\log$ scale) and fallout ${ }^{137} \mathrm{Cs}$ at two locations in southern Lake Huron. $(O=1974$ data; $\bullet=1975$ data). The solid line represents the distribution of $210 \mathrm{~Pb}$ expected if rapid steady-state mixing (equation 6) occurs at the sediment-water interface (least squares fit). The dashed lines represent the expected distribution of ${ }^{137} \mathrm{Cs}$ with various assumed depths of mixing (equation 8 ; arbitrary normalization). The gradual fall-off in ${ }^{137} \mathrm{Cs}$ activity may reflect the decrease in the time-integrated distribution of benthic macroinvertebrates near the mixed-zone boundary. 
just below the mixed zone would be:

$A^{-}=A_{\mathrm{s}} \mathrm{e}^{-\lambda s / \omega}$

After coring, the activity within the mixed zone would be the average:

$A^{+}=A_{\mathrm{s}} \cdot \frac{1}{s} \int_{0}^{s} \mathrm{e}^{-\lambda z / \omega} \mathrm{d} z$

Thus under such conditions the ratio of activity in the mixed zone to that directly below is markedly discontinuous. Evaluating the integral in equation 2 gives:

$A^{+} / A^{-}=\frac{\omega}{s \lambda}\left(\mathrm{e}^{\lambda s / \omega}-1\right)$

which equals 2.5 for the distributions at station 14 . We do not see such a discontinuity in the data. In order to produce a ${ }^{210} \mathrm{~Pb}$ profile on coring with constant activity above $6 \mathrm{~cm}$ and with an exponential form immediately below $6 \mathrm{~cm}$ it would be necessary to start with a profile in undisturbed sediments significantly different from that given by equation 1 . To us a simpler explanation is more attractive.
The distributions of unsupported ${ }^{210} \mathrm{~Pb}$ have a form consistent with the process of rapid steady-state mixing. The theoretical distribution shown in Fig. 1 is the result of a least squares fit using equation 6 and the $1975{ }^{210} \mathrm{~Pb}$ data. Values of $A_{s}, \omega$ and $s$ obtained from the least squares analysis are given in Table 1. Note that the model predicts a large difference between the activity of unsupported ${ }^{210} \mathrm{~Pb}, A_{\mathrm{s}}$, in material just prior to its incorporation into sediments and the observed activity, $A_{\mathrm{m}}$, at the sediment-water interface. The values of the ratio $A_{\mathrm{s}} / A_{\mathrm{m}}=(1+\lambda s / \omega)$ (equation 5) are 2.6 and 1.6 at stations 14 and 18 , respectively. The ages associated with the base of the mixed zone, $t^{*}=s / \omega$ (see Guinasso and Schink [29]), are 52 and 20 years at stations 14 and 18 , respectively. The time $t *$ is the residence time of a particle within the mixed zone and represents a lower limit to the resolution with which the history of time-dependent fluxes to the sediments can be reconstructed from these cores. Note that while we have chosen to refer to the region of approximately constant ${ }^{210} \mathrm{~Pb}$ activity as the "mixed zone", without additional information we cannot rule out the possibility that mixing occurs below this zone although it

TABLE 1

Sedimentation and mixing parameters for Lake Huron cores

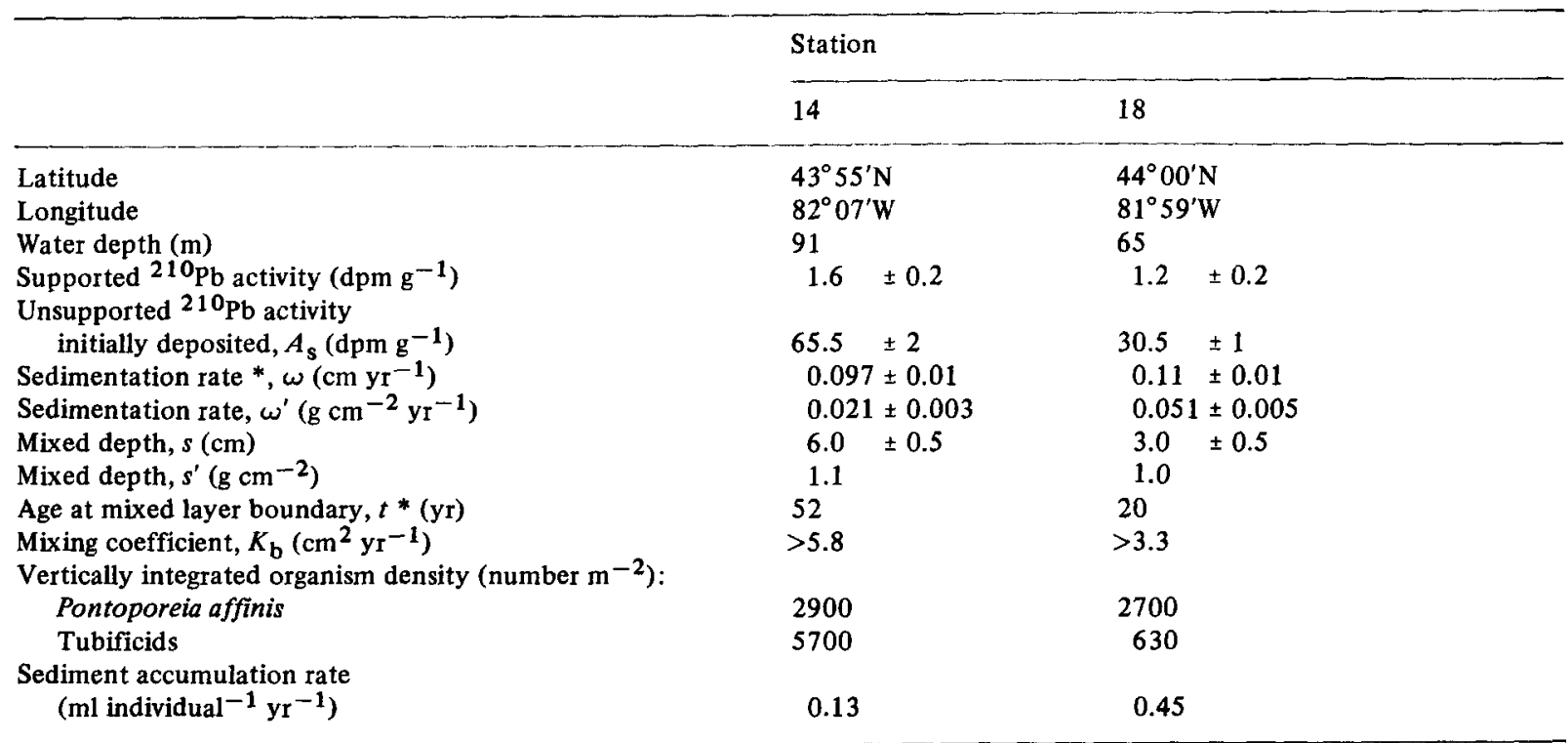

* Average over the upper $10 \mathrm{~cm}$ (i.e. $\omega=10 / \Delta t ; \Delta t=$ cumulative $\mathrm{g} \mathrm{cm}^{-2}$ at $10 \mathrm{~cm} / \omega^{\prime}$ ) 
would have to be to a considerably smaller extent. For finite values of $K_{\mathrm{b}}$ the solution of equation 10 yields a theoretical distribution of ${ }^{210} \mathrm{~Pb}$ which decreases exponentially within the mixed zone $[8,9,28]$. Provided the mixing process has an eddy diffusive character it is impossible to distinguish between sedimentation and mixing effects on the basis of ${ }^{210} \mathrm{~Pb}$ profiles alone [9]. Hence the exponential decrease in unsupported ${ }^{210} \mathrm{~Pb}$ activity below the mixed zone could partly or wholly arise from eddy diffusional mixing as well. However, two sources of information indicate little mixing below the zone of constant ${ }^{210} \mathrm{~Pb}$ activity. First, we have observed thin (submillimeter) black banding of sediments just below but not in the mixed zone in cores from each location. Second, deposit-feeding organisms do not occur in significant numbers below the mixed zone as defined by radioactivity profiles.

The distributions of Pontoporeia affinis and tubificid oligochaetes at stations 14 and 18 are shown in Fig. 2 in terms of numbers per core per centimeter interval. It can be seen that significant animal densities occur only within the zone of constant ${ }^{210} \mathrm{~Pb}$ activity. At station 14 oligochaete worms and amphipods account for $94 \%$ of all macrobenthos found, while at station 18 that group accounts for $82 \%$ of the total. At this latter site the mollusc, Pelecypoda (Pisidium), occurs in significant numbers

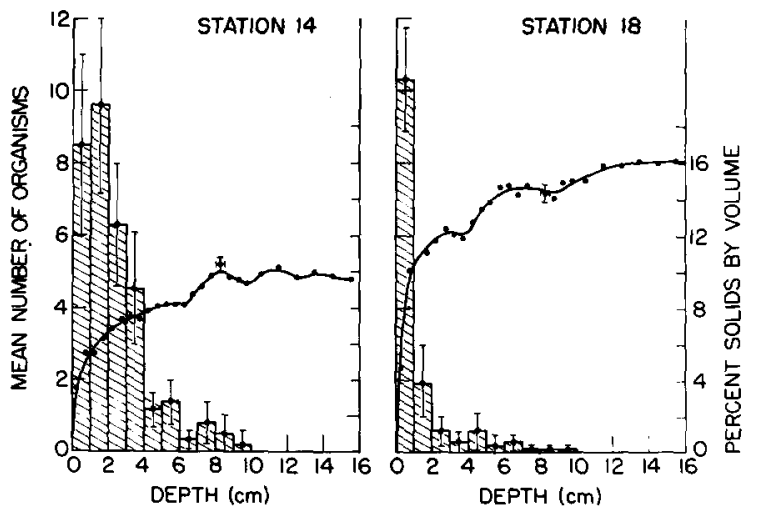

Fig. 2. The mean number of Pontoporeia affinis and tubificid oligochaetes per core per cm interval in August 1975. These deposit-feeding animals occur at depths comparable to radioactivity mixing depths. The distribution of percent solids (solid curve) rises abruptly below the mixed zone where compaction is not impeded by organism activity. accounting for an additional $17 \%$ of the total faunal inventory. An analysis of zoobenthos abundance and composition is reported elsewhere [20]. At station $14,95 \%$ of the organisms occur above the $6 \mathrm{~cm}$ depth defined by ${ }^{210} \mathrm{~Pb}$ while at station $18,90 \%$ occur above $3 \mathrm{~cm}$. This is evidence that the predominant mobile infaunal macroinvertebrates homogenize sediment solids and strongly associated or adsorbed ${ }^{210} \mathrm{~Pb}[9,11]$ and ${ }^{137} \mathrm{Cs}[22,23]$. The vertical distributions of the proportion of solids (Fig. 2) provide additional evidence of the dominance of biological mixing processes. An abrupt increase in percent solids occurs just below the mixed zone where compaction is not impeded by organism activity $[20,25]$.

While we cannot rule out the possibiltiy that mixing is produced in part by bottom currents (resuspension) or by the formation of bubbles, the densities of the larger zoobenthos (Table 1) are probably sufficient to homogenize sediments within the mixed zone even without the assistance of such nonbiological mixing processes. In the case of the worms (mainly Tubificidae) subsurface feeding and surface defecation result in transport of sediment from within the mixed zone to the sediment-water interface $[15,26]$. Complete homogenization will occur if the sediment displacement (feeding-defecation) rate is comparable to or exceeds the sediment accumulation rate per deposit-feeding individual. At the prevailing in-situ temperature of profundal sediments $\left(4-6^{\circ} \mathrm{C}\right)$ the displacement rate is probably at least $3 \mathrm{ml}$ bulk sediment worm ${ }^{-1} \mathrm{yr}^{-1}$ or $0.14 \mathrm{~g}$ dry sediment worm $^{-1}[20,26]$. This displacement rate, estimated from published data compiled by Davis [15], is probably conservative. His own measurements indicate a rate for tubificids 2-3 times higher than our adopted value. This rate greatly exceeds the bulk sediment accumulation rate of $0.2 \mathrm{ml} \mathrm{yr}^{-1}$ worm ${ }^{-1}$ or $0.036 \mathrm{~g}$ dry sediment worm ${ }^{-1} \mathrm{yr}^{-1}$ at station 14. Although worms are less numerous and the sediment accumula. tion rate per worm consequently higher at station $18\left(2.4 \mathrm{ml} \mathrm{worm}^{-1} \mathrm{yr}^{-1}\right)$, this rate is still comparable to our conservative estimate of the displacement rate. (We estimated bulk sediment accumulation rates for comparison with published reworking rates in the following way. The volume of bulk sediment within the mixed zone is $\Delta V=s \cdot A$ where $A$ is the cross-sectional area of the core, $35.5 \mathrm{~cm}^{2}$. The age corresponding to the base of the mixed zone is then $\Delta t=s^{\prime} / \omega^{\prime}$ 
where $s^{\prime}$ and $\omega^{\prime}$ are values of $s$ and $\omega$ in $\mathrm{g} \mathrm{cm}^{-2}$ and $\mathrm{g} \mathrm{cm}^{-2} \mathrm{yr}^{-1}$, respectively. The bulk sediment accumulation rate per individual is then taken as $\Delta V /(N \Delta t)$ where $N$ is the number of individuals within the mixed zone. This method of calculation corrects for the effects of compaction within the mixed zone.) The contribution to sediment mixing by Pontoporeia affinis, which has similar population densities at the two sites, is not known. However, this amphipod is generally much larger than tubificids and burrows and feeds actively below the sediment surface [27]. Therefore, we may conservatively assume that they have displacement rates comparable to those of worms, although the way in which they mix sediments probably differs from that of the worms. The total displacement rate then greatly exceeds the projected accumulation rate per deposit-feeding individual of 0.13 (station 14) and 0.45 (station 18) $\mathrm{ml}$ individual $^{-1} \mathrm{yr}^{-1}$. Thus oligochaetes alone can account for mixing at station 14 while the effects of amphipods (and possibly Pisidium) may have to be included at station 18. In terms of eddy diffusional mixing we estimate that values of $K_{\mathrm{b}}$ must be greater than or approximately equal to 5.8 and $3.3 \mathrm{~cm}^{2} \mathrm{yr}^{-1}$ at stations 14 and 18 , respectively (see equation 11 ). These values are within the range of values derived by Guinasso and Schink of $1-10 \mathrm{~cm}^{2} \mathrm{yr}^{-1}$ for mixing of estuarine sediments by Yoldia limatula [30] and in the vicinity of the value of $1.4 \mathrm{~cm}^{2}$ $\mathrm{yr}^{-1}$ for mixing of lake sediments by tubificids [15].

Additional insight into the process of mixing can be gained from analysis of the distributions of ${ }^{137} \mathrm{Cs}$. As the residence time of this fallout radionuclide $\left(t_{1 / 2}=30\right.$ years $)$ in the lakes is very short, about one year in Lake Huron [31], its concentration in the water closely parallels the history of atmospheric inputs [32]. Thus in undisturbed sediments this historical record should also be apparent. Such a hypothetical distribution in undisturbed sediments $(s=0$, Fig. 1) approximates a tracer pulse located at a sediment depth determined on the basis of the ${ }^{210} \mathrm{~Pb}$ sedimentation rate. The actual ${ }^{137} \mathrm{Cs}$ distribution is not well-described by introducing variable amounts of mixing (e.g. $s=3$ or $6 \mathrm{~cm}$, station 14 , Fig. 1) using the steady-state mixing model (equations 7,8 ) with time-dependent ${ }^{137} \mathrm{Cs}$ inputs. The calculated ${ }^{137} \mathrm{Cs}$ distribution decreases too sharply at the mixed zone boundary. Application of the eddy diffusion model (equation 10) with sufficiently small values of $K_{\mathrm{b}}$ would allow the activity near the boundary to be reproduced but would produce incomplete homogenization within the mixed zone contrary to our measured distributions. Lerman and Lietzke [33] have suggested that molecular diffusion is an important factor in the post-depositional mobility of ${ }^{137} \mathrm{Cs}$ in sediments of the Great Lakes. This process could result in broadening the distribution of the ${ }^{137} \mathrm{Cs}$ activity at the mixed zone boundary. The effective molecular diffusion coefficient of nonabsorbing ions in sediment is approximated as $D_{\mathrm{m}}=D_{0} \alpha / \theta^{2}$ [34] where the factor $\alpha / \theta^{2}$ is close to unity in these sediments and $D_{0}$ is the diffusion coef. ficient in free solution $\left(\sim 5 \times 10^{-6} \mathrm{~cm}^{2} \mathrm{sec}^{-1}=160\right.$ $\mathrm{cm}^{2} \mathrm{yr}^{-1}$ ). If ions adsorb and desorb reversibly on sediment solids according to the Freundlich adsorption isotherm (with $n=1$, see Lerman and Lietzke [33]), then the effective molecular diffusion coefficient is $D_{\mathrm{m}}=D_{\mathrm{m}} /(1+K)$ where $K$ is the dimensionless ratio of activity on solids and in solution at equilibrium. For surface sediments at station 14 we have measured a value of $K=4000$ for ${ }^{137} \mathrm{Cs}$ which gives:

$D_{\mathrm{m}}^{\prime}=D_{0} \frac{\alpha}{\theta^{2}} \frac{1}{1+K} \sim 0.04 \mathrm{~cm}^{2} \mathrm{yr}^{-1}$

Thus within the mixed zone and throughout most of the transition region (where ${ }^{137} \mathrm{Cs}$ activity decreases rapidly) the values of $K_{\mathrm{b}}$ are at least two orders of magnitude higher than the effective molecular diffusion coefficient. Thus it would seem more likely that the gradual decrease in activity near the mixedzone boundary reflects the decrease in the probability of the occurrence of a mixing event with increasing depth. The necessity for introducing a eddy diffusion coefficient varying continuously with depth has been noted by Guinasso and Schink [29]. Also Pennington et al. [35] considered that the indefinite "tails" on the distributions of ${ }^{137} \mathrm{Cs}$ in sediment cores from Blelham Tarn result from faunal mixing. Our results suggest that for profundal sediments of the Great Lakes, the vertical dependence of $K_{\mathrm{b}}$ may be approximated as the time-integrated density distribution of the two predominant macrofaunal species which can mix near-surface sediments. That is:

$K_{\mathrm{b}}(z) \sim \frac{1}{T} \int_{0}^{T}\left[K_{1} \rho_{1}(z, t)+K_{2} \rho_{2}(z, t)\right] \mathrm{d} t$ 
where $\rho_{1}$ and $\rho_{2}$ are the densities of oligochaetes and Pontoporeia affinis (number $\mathrm{ml}^{-1}$ ), respectively at depth $z$ and time $t$. The averaging interval, $T$, is sufficiently long $>1$ year) to include variations in seasonal abundance. This representation would seem to be most appropriate where instantaneous reworking is localized within a sediment thickness which is small compared to the extent of the mixed zone. By comparing the vertical distribution of ${ }^{137} \mathrm{Cs}$ with the vertical distributions of deposit-feeding animals in a series of cores from significantly differing locations, the relative contributions of various species to eddy diffusional mixing could be separated provided the above formalism (equation 16) which explicitly assumes non-interacting populations is correct. The depth dependence of $K_{\mathrm{b}}$ implied by the ${ }^{137} \mathrm{Cs}$ distributions is not inconsistent with the ${ }^{210} \mathrm{~Pb}$ data. The distribution of ${ }^{210} \mathrm{~Pb}$ is much less sensitive than that of ${ }^{137} \mathrm{Cs}$ to incomplete homogenization near the mixed-zone boundary. This depth-dependent form of $K_{\mathrm{b}}$ will generate a theoretical ${ }^{210} \mathrm{~Pb}$ distribution with rounded rather than sharp corners. Such a distribution is no less consistent with the observed distributions of ${ }^{210} \mathrm{~Pb}$.

We find that the constant activity of ${ }^{210} \mathrm{~Pb}$ and ${ }^{137} \mathrm{Cs}$ just below the sediment-water interface is correlated with the vertical distribution of mobile macroinvertebrates in selected cores from Lake Huron. As constant near-surface activities of these radionuclides occur widely in profundal fine-grained sediments of Lakes Michigan, Huron and Superior and zoobenthic densities and composition are similar in each lake, although somewhat lower in Lake Superior [36], we conclude that the effect of mobile macroinvertebrates on the physical and chemical properties of near-surface sediments must be considered in studies of sediment geochemistry, interface transport processes, and in the use of recent sedimentary records to reconstruct the history of timedependent deposition processes in the Great Lakes.

\section{Acknowledgements}

We thank the crew of the $R / V$ "Simons" for their help in sample acquisition, K. Johansen and G. Burin for their assistance in radioactivity measurements, and R.O. Brinkhurst, E.D. Goldberg, A. Lerman, C.
Martens and K.K. Turekian for their initial comments. We than D. Schink and N. Guinasso especially for their help in revision of this article. This work was supported in part by an EPA Grant R-804686-01 and by Argonne National Laboratory Subcontract 31109-38-2468 to J.A. Robbins. Contribution No. 216 of the Great Lakes Research Division, University of Michigan, Ann Arbor, Michigan 48109.

\section{References}

1 D.N. Edgington and J.A. Robbins, Records of lead deposition in Lake Michigan sediments since 1800 , Environ. Sci. Technol. 10 (1976) 266.

2 D.N. Edgington and J.A. Robbins, The behavior of plutonium and other long-lived radionuclides in Lake Michigan, II. Patterns of deposition in sediments. In: Impacts of Nuclear Release into the Aquatic Environment (IAEA, Vienna, 1975) 245.

3 J.A. Robbins and D.N. Edgington, Determination of recent sedimentation rates in Lake Michigan using lead210 and cesium-137, Geochim. Cosmochim. Acta 39 (1975) 285.

4 K.A. Johansen and J.A. Robbins, Fallout cesium-137 in sediments of southern Lake Huron and Saginaw Bay, 20th Annu. Conf. on Great Lakes Research of Int. Assoc. Great Lakes Research, Ann Arbor, Mich., May 10-12, 1977 (abstract).

5 J.A. Robbins, Recent sedimentation rates in southern Lake Huron and Saginaw Bay, 40th Annu. Meet. Am. Soc. Limnol. Oceanogr., Lansing, Mich., June 20-23, 1977 (abstract).

6 K.W. Bruland, M. Koide, C. Bowser, L.J. Maher and E.D. Goldberg, Lead-210 and pollen geochronologies on Lake Superior sediments, Quatern. Res. 5 (1975) 89.

7 S. Krishnaswami, D. Lal, J.J. Martin and M. Meybeck, Geochronology of lake sediments, Earth Planet. Sci. Lett. 11 (1971) 407.

8 K.W. Bruland, Lead-210 geochronology in the coastal marine environment, Ph.D. Dissertation, Univ. of California, San Diego, Calif. (1974).

9 J.A. Robbins, Geochemical and geophy sical applications of radioactive lead isotopes, in: Biogeochemistry of Lead, J.O. Nriagu, ed. (Elsevier, Amsterdam, 1977) in press.

10 S.E. Poet, H.E. Moore and E.A. Martell, Lead-210, bismuth-210 and polonium-210 in the atmosphere: accurate ratio measurement and application to aerosol resistence time determination, J. Geophys. Res. 77 (1972) 6515.

11 L.K. Benninger, D.M. Lewis and K.K. Turekian, The use of natural lead-210 as a heavy metal tracer in the riverestuarine system, in: Marine Chemistry in the Coastal Environment, Am. Chem. Soc. Symp. Ser. 18 (American Chemical Society, Washington, D.C. 1975) 202.

12 S. Thomson, K.K. Turekian and J. McCaffrey, The 
accumulation of metals in and release from sediments of Long Island Sound, in: Estuarine Research, 1, L.E. Cronin, ed. (Academic Press, New York, N.Y., 1975) 28.

13 R.C. Aller and J.K. Cochran, ${ }^{234} \mathrm{Th} /{ }^{238} \mathrm{U}$ disequilibrium in near-shore sediment: particle reworking and diagenetic time scales, Earth Planet. Sci. Lett. 29 (1976) 37.

14 W.P. Alley and S.C. Mozley, Seasonal abundance and spatial distribution of Lake Michigan macrobenthos, 19641967, Great Lakes Res. Div., Univ. of Michigan, Ann Arbor, Mich., Spec. Rep. 54 (1975) 103 pp.

15 R.B. Davis, Stratigraphic effects of tubificids in profundal lake sediments, Limnol. Oceanogr. 19 (1974) 466.

16 R.B. Davis, Tubificids alter profiles of redox potential and $\mathrm{pH}$ in profundal lake sediment, Limnol. Oceanogr. 19 (1974) 342.

17 J.F. Flannagan, Efficiencies of various grabs and corers in sampling freshwater benthos, J. Fish. Res. Board Can. 27 (1970) 1961.

$18 \mathrm{G}$. Milbrink, On the vertical distribution of oligochaetes in lake sediments, Rep. Inst. Freshwater Res. Drottningholm 53 (1973) 34.

19 R.L. Thomas, A.W.L. Kemp and C.F.M. Lewis, Surficial sediments of Lake Huron, Can. J. Earth. Sci. 10 (1973) 226.

20 J.R. Krezoski, S.C. Mozley and J.A. Robbins, Influence of benthic macroinvertebrates on mixing of profundal sediments in Lake Huron, Limnol. Oceanogr. (1977) in press.

21 W.H. Berger and G.R. Heath, Vertical mixing in pelagic sediments, J. Mar. Res. 26 (1968) 134-143.

22 S.R. Aston and E.K. Duursma, Concentration effects on ${ }^{137} \mathrm{Cs},{ }^{65} \mathrm{Zn},{ }^{60} \mathrm{Co}$ and ${ }^{106} \mathrm{Ru}$ sorption by marine sediments, with geochemical implications, Neth. J. Sea Res. 6 (1973) 225.

23 E.K. Duursma and C.J. Bosch, Theoretical, experimental and field studies concerning diffusion of radioisotopes in sediments and suspended particles of the sea, B. Methods and experiments, Neth. J. Sea Res. 4 (1970) 395.

24 D.C. Rhoads, Organism-sediment relations on the muddy sea floor, Oceanogr. Mar. Biol. Annu. Rev. 12 (1974) 263.
25 R.L. McMaster, Compactness variability of estuarine sediments: an in situ study, in: Estuaries, G.H. Lauff, ed. (Association of the Advancement of Sciences, Washington, D.C., 1967) 83: 261.

26 A.G. Appleby and R.O. Brinkhurst, Defecation rate of three tubificid oligochaetes in the sediment of Toronto Harbor, Ontario, J. Fish. Res. Board Can. 27 (1970) 1971.

27 W.P. Alley, Ecology of the burrowing amphipod Pontoporeia affinis in Lake Michigan, Great Lakes Res. Div., Univ, of Michigan, Ann Arbor, Mich. Spec. Rep. 36 (1968).

28 E.D. Goldberg and M. Koide, Geochronological studies of deep sea sediments by the ionium/thorium method, Geochim. Cosmochim. Acta 26 (1962) 417.

29 N.L. Guinasso and D.R. Schink, Quantitative estimates of biological mixing rates in abyssal sediments, J. Geophys. Res. 80 (1975) 3032.

30 D.C. Rhoads, Rates of sediment reworking by Yoldia limatula in Buzzards Bay, Massachusetts, and Long Island Sound, J. Sediment. Petrol. 33 (1963) 723.

31 P.J. Barry, Estimating dose commitments to populations from radioactive waste disposals into large lakes, in: Environmental Behavior of Radionuclides Released in the Nuclear Industry (IAEA, Vienna, 1973) 499-505.

32 Health and Safety Laboratory Fallout Program, USAEC, HASL-258, A-40-41, A-93-94 (1972).

33 A. Lerman and T.A. Lietzke, Uptake and migration of tracers in lake sediments, Limnol. Oceanogr. 20 (1975) 497.

34 Y.H. Li and S. Gregory, Diffusion of ions in seawater and in deep-sea sediments, Geochim. Cosmochim. Acta 38 (1974) 703.

35 W. Pennington, R.S. Cambray, J.D. Eakins and D.D. Harkness, Radionuclide dating of the recent sediments of Blelham Tarn, Freshwater Biol. 6 (1976) 317.

36 D.G. Cook and M.G. Johnson, Benthic macroinvertebrates of the Saint Lawrence Great Lakes, J. Fish. Res. Board Can. 31 (1974) 763. 